\title{
Simulation of a Spherical Wave Experiment in Marble Using A Multidirectional Damage Model
}

\author{
T. H. Antoun, I. N. Lomov
}

This article was submitted to $13^{\text {th }}$ APS SCCM Conference, Portland, Oregon, Week of July 21, 2003

U.S. Department of Enargy

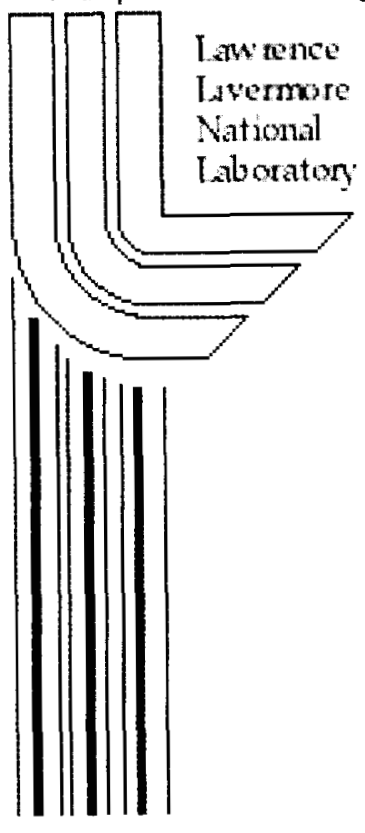

July 18, 2003 


\section{DISCLAIMER}

This document was prepared as an account of work sponsored by an agency of the United States Government. Neither the United States Government nor the University of California nor any of their employees, makes any warranty, express or implied, or assumes any legal liability or responsibility for the accuracy, completeness, or usefulness of any information, apparatus, product, or process disclosed, or represents that its use would not infringe privately owned rights. Reference herein to any specific commercial product, process, or service by trade name, trademark, manufacturer, or otherwise, does not necessarily constitute or imply its endorsement, recommendation, or favoring by the United States Government or the University of California. The views and opinions of authors expressed herein do not necessarily state or reflect those of the United States Government or the University of California, and shall not be used for advertising or product endorsement purposes.

This is a preprint of a paper intended for publication in a journal or proceedings. Since changes may be made before publication, this preprint is made available with the understanding that it will not be cited or reproduced without the permission of the author.

This work was performed under the auspices of the United States Department of Energy by the University of California, Lawrence Livermore National Laboratory under contract No. W-7405-Eng-48.

This report has been reproduced directly from the best available copy.

Available electronically at http://www.doc.gov/bridge

Available for a processing fee to U.S. Department of Energy

And its contractors in paper from

U.S. Department of Energy

Office of Scientific and Technical Information

P.O. Box 62

Oak Ridge, TN 37831-0062

Telephone: (865) 576-8401

Facsimile: (865) 576-5728

E-mail: reports@adonis.osti.gov

Available for the sale to the public from

U.S. Department of Commerce

National Technical Information Service 5285 Port Royal Road Springfield, VA 22161

Telephone: (800) 553-6847

Facsimile: (703) 605-6900

E-mail: orders@ntis.fedworld.gov

Online ordering: http://www.ntis.gov/ordering.htm

\section{OR}

Lawrence Livermore National Laboratory

Technical Information Department's Digital Library

http://www.llnl.gov/tid/Library.html 


\title{
SIMULATION OF A SPHERICAL WAVE EXPERIMENT IN MARBLE USING A MULTIDIRECTIONAL DAMAGE MODEL
}

\author{
Tarabay H. Antoun, Ilya N. Lomov \\ Earth Sciences Division, Lawrence Livermore National Laboratory, Livermore CA 94551
}

\begin{abstract}
This paper presents experimental results and computational simulations of spherical wave propagation in Danby marble. The experiment consisted of a 2-cm-diameter explosive charge detonated in the center of a cylindrical rock sample. Radial particle velocity histories were recorded at several concentric locations in the sample. An extensively damaged region near the charge cavity and two networks of cracks were evident in the specimen after the test. The first network consists of radial cracks emanating form the cavity and extending about halfway through the specimen. The second network consists of circumferential cracks occurring in a relatively narrow band that extends from the outer boundary of the radially cracked region toward the free surface. The experiment was simulated using the GEODYN code and a multi-directional damage model. The model is developed within the framework of a properly invariant nonlinear thermomechanical theory with damage represented by a second order tensor that admits load-induced anisotropy such as was observed in the experiment.
\end{abstract}

\section{INTRODUCTION}

Wave propagation in multi-layered geologic media involves wave reflections, which, under certain conditions, can give rise to states of tensile stress. Tensile stresses also arise in the hoop direction behind the shock front in spherically divergent flows, such as in the vicinity of an underground explosion. Tensile failure is common under these circumstances because geologic materials are weaker in tension than they are in compression. The brittle nature of this tensile failure imparts a directional dependence to the damage field, which in turn leads to load-induced anisotropy. This damage process can significantly alter the late-time stress and deformation histories in the medium. Thus, for applications requiring knowledge of the complete deformation history, like simulating the response of underground structures to impulsive loading, an ability to compute multidirectional cracking within a continuum mechanics framework is essential. A multidirectional cracking model was recently developed [1]. This paper describes an application of the model to simulate directional damage in an explosively-loaded sample of Danby marble.

\section{SPHERICAL WAVE EXPERIMENT}

The configuration of the spherical wave experiment is shown in Fig. 1. In the experiment, a 2-cm-diameter EL-506D (Detasheet) explosive charge weighing $6 \mathrm{~g}$ was detonated at the center of an instrumented 27-cm-diameter, 27-cm-long cylindrical block of marble [2]. The specimen assembly was placed inside a pressure vessel wherein it was subjected to a $6.9 \mathrm{MPa}$ static overburden pressure. Particle velocity histories at several radii from the charge were measured by monitoring the motion of embedded wire gages through an externally applied magnetic field. Two diametrically opposite gages were used at each of eight radii starting at the charge boundary and extending outward to a radius of $5.0 \mathrm{~cm}$. The gages 
at the two ranges closest to the charge experienced premature failure leading to loss of data at these locations. The velocity histories at the remaining ranges are shown in Fig. 2. The letters $a$ and $b$ following the gage number are used to distinguish the two gage arrays on opposite sides of the charge.

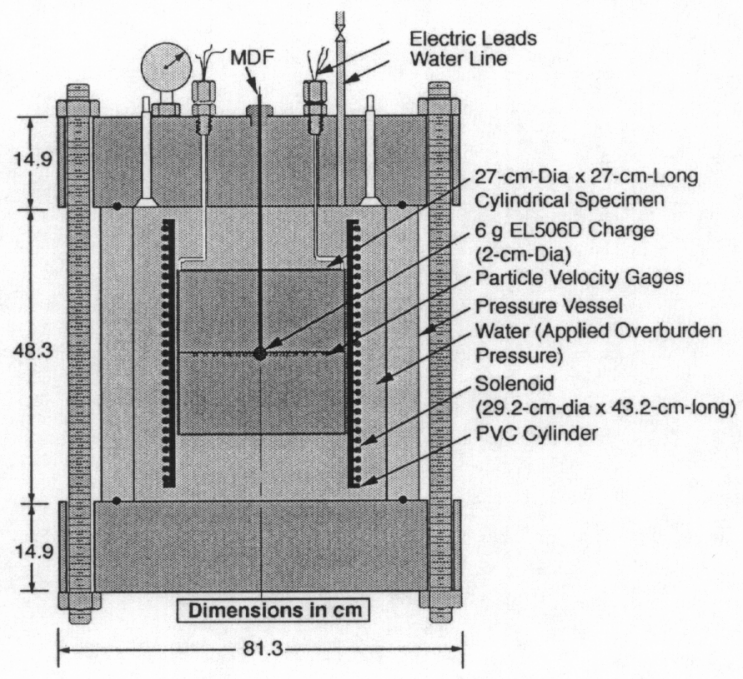

Figure 1. Spherical wave experimental setup.

At early times, the recorded velocity histories are characterized by a sharp rise to peak followed by an outward motion that lasts for about $10 \mathrm{~s}$. This early-time response is reproducible, as indicated by the nearly identical records from the gage arrays on either side of the charge. The outward expansion phase is followed by a rebound phase. In previous experiments $[3,4]$, the rebound signal caused an inward contraction in the motion of the rock sample that was manifested by a reversal of the sign of the particle velocity histories. In the present experiment, the particle velocities recorded at all ranges remained positive throughout the rebound phase of the signal. This difference between the rebound signals measured in the present experiment and those measured in other investigations can be related to cracking of the rock sample. Extensive cracking was not observed in either of the two studies cited above. In contrast, the Danby marble specimen of the present study was severely cracked, as shown in Fig. 3. In addition to the extensively damaged region near the charge cavity, two distinct networks of cracks can be seen in each half of the specimen. The first network consists of numerous cracks emanating from the charge boundary and extending radially outward toward the free surface of the specimen. These radial cracks extend throughout the gaged region of the specimen, and a few cracks propagate all the way to the free surface. The second network of cracks consists primarily of circumferential cracks and does not appear to be symmetric with respect to the center of the explosive charge. An additional crack that does not appear to be associated with either of the crack networks mentioned so far can be observed spanning the whole specimen surface. This crack follows the path of a pre-existing in situ joint in the rock. The extensive cracking in the Danby marble specimen caused degradation of the material properties and reduced the stiffness of the rock. For this reason, the response of the specimen during unloading was substantially different from its initial intact response. Consequently, much of the early-time deformation was not recovered during the contraction, or rebound, phase.

The results of the spherical wave experiment also show evidence of load-induced anisotropy, a response mode usually associated with cracking in brittle materials. This anisotropy is manifested as a difference in the recorded particle velocity histories along the two different gage arrays of the spherical wave experiment. This occurs during the rebound phase of the response and can be seen in the results shown in Fig. 2. A careful comparison of the results shown in the figure reveals a systematic difference between the late-time particle velocity histories recorded by gages in the a array and those recorded by gages in the $b$ array. A single rebound signal with duration of about 15-17 $\mathrm{s}$ is observed on the a side of the specimen. In contrast, a two-spike rebound signal is observed on the $b$ side of the specimen. The first spike has a larger amplitude and longer duration than the second spike, but when the two spikes on the $b$ side of the specimen are combined, they have the same duration as the single spike on the a side. We believe that these systematic differences are due to the effects of cracks on wave propagation. Specifically, the lack of symmetry in the cracking patterns caused the stress wave to become asymmetric, and thus gages located in different regions of the specimen recorded different motions. 

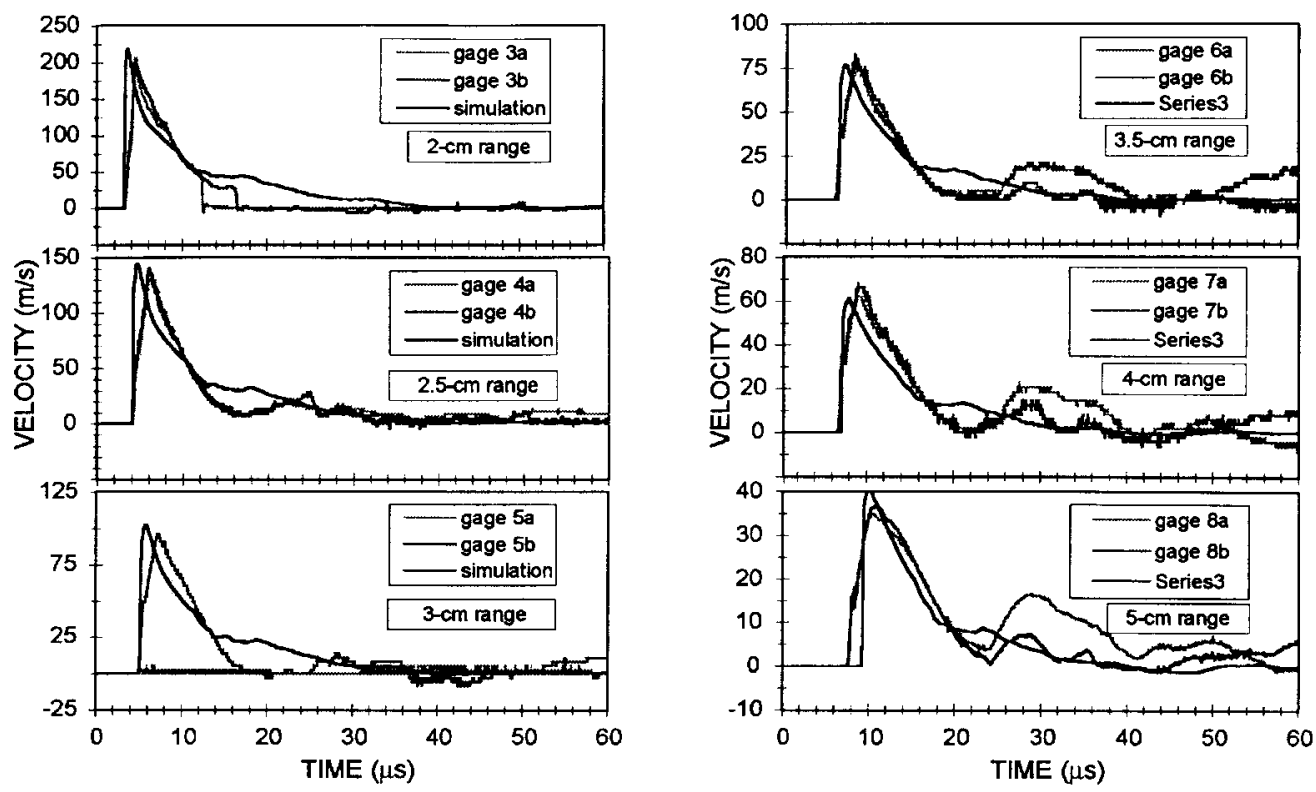

Figure 2. Measured and simulated particle velocity histories at 6 radii from the explosive charge.

\section{NUMERICAL SIMULATIONS}

A continuum model that can simulate weakening and void formation due to directional tensile failure was used in the simulations. The model is developed within the context of a properly invariant nonlinear thermomechanical theory. A second order damage tensor is introduced which allows simulation of weakening to tension applied in one direction, without weakening to subsequent tension applied in perpendicular directions. This tensor can be advected using standard methods. Porosity is used as a measure of volumetric void strain and its evolution is influenced by tensile failure. The rate of dissipation due to directional tensile failure takes a particularly simple form, which can be analyzed easily. The model is combined with constitutive equations for porous compaction and dilation, as well as viscoplasticity. A robust non-iterative numerical scheme is used for integrating the evolution equations.

The model was calibrated using laboratory data that included elastic properties, unconfined compressive strength, and a pressure dependent failure surface. Pressure-volume data from 1D strain wave propagation experiments were also used to calibrate the Mie-Gr neisen EOS used in the simulations. Material parameters that could not be determined from the aforementioned data were determined through an optimization process using the measured particle velocity histories shown earlier in Fig 2. As shown in the figure, the calibrated model is in good agreement with the data at early time, when the flow field can be reasonably viewed as spherically symmetric. At late time, reflected waves from the cylindrical boundary of the specimen converge toward the charge cavity and in so doing render the flow field three-dimensional. Also at late time, the sample response becomes anisotropic due to the interaction of the stress waves with pre-existing planes of weakness in the sample. These two phenomena cause a breakdown in the 2D axisymmetry assumption. For this reason no attempt was made to match the late time velocity histories.

The damage patterns computed with the calibrated model are shown in Fig. 4. The two halves of the figure show void volume fraction and crack patterns, both of which are indication of damage. The main difference between the two is that void volume fraction is reversible (i.e., voids can undergo recompaction under compression) whereas damage is irreversible, increasing under tension and remaining constant under compression. 


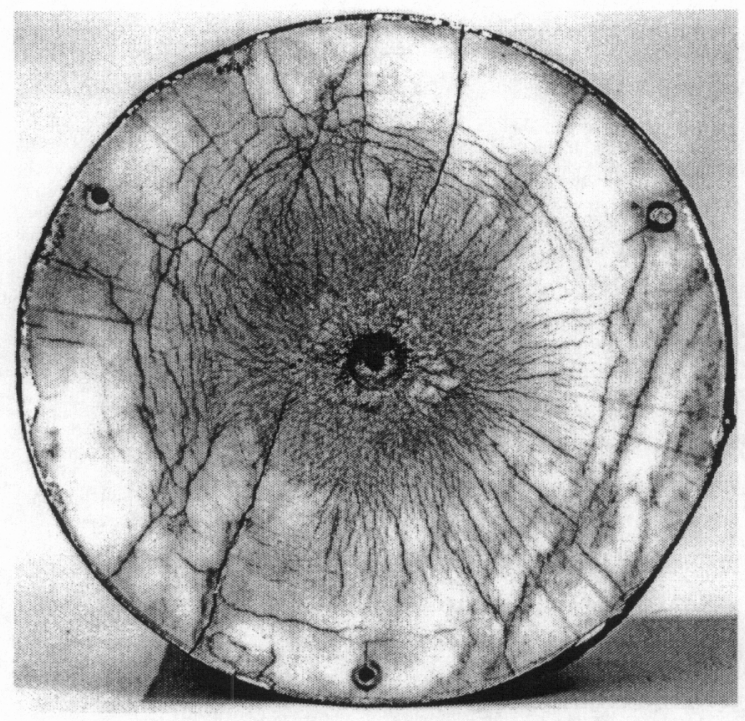

Figure 3. Observed damage at the midsection of the explosively loaded Danby marble specimen.

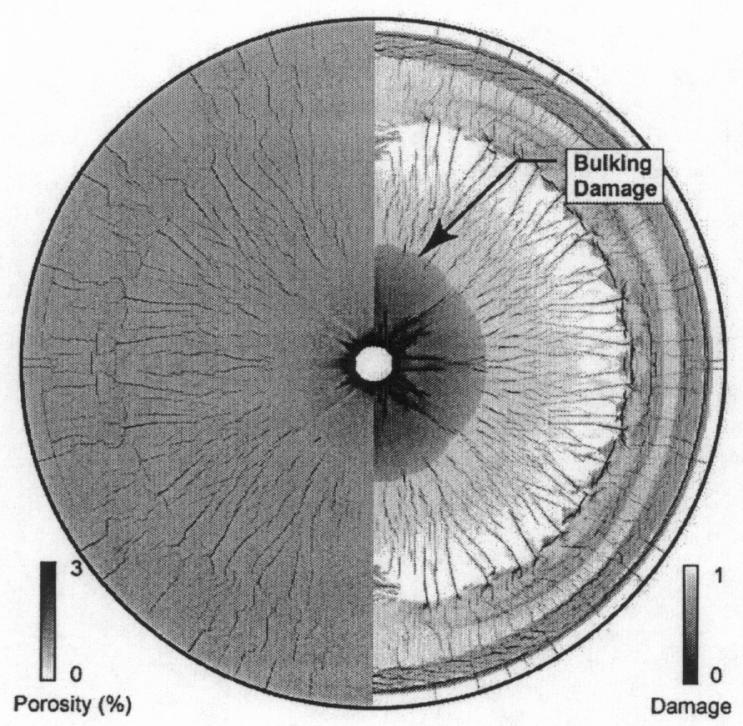

Figure 4. Void volume and directional damage from the 2D simulation of the spherical wave experiment

These patterns look remarkably similar to the cracking patterns observed in the experiment. Like in the experiment, two crack networks are observed; the first consisting of radial cracks propagating away from the charge cavity toward the free surface, and the second consisting of rings of circumferential cracks caused by the reflected wave near the free surface of the specimen. The simulated circumferential cracks network is closer to the surface of the specimen than was observed experimentally. This is probably because in the simulation the reflected wave is spherically symmetric, and therefore more intense than its cylindrically symmetric counterpart in the experiment.

Fig. 4 appears not to show extensive damage near the cavity as observed in the experiment. This apparent disagreement is due to the fact that in the model, damage near the source is dominated by plastic distortion and bulking. Bulking porosity as high as $3 \%$ was computed in the near-source region where extensive cracking was not observed.

The 2D simulations are in reasonably good agreement with the data indicating that our multidimensional cracking model is well suited for simulating directional damage within a continuum mechanics framework. To improve agreement with data, a 3D simulation is needed to properly account for specimen geometry, including preexisting joints, and for the complex wave interactions that take place during the later stages of the experiment.

\section{ACKNOWLEDGEMENTS}

This work was performed under the auspices of the U.S. Department of Energy by the University of California, Lawrence Livermore National Laboratory under contract No. W-7405-Eng-48.

\section{REFERENCES}

1. Rubin M.B., and Lomov I.N., Mechanical and Numerical Modeling of a Porous ElasticViscoplastic Material with Tensile Failure, submitted to Int. J. Solids Struct.

2. Antoun, T.A., Curran, D.R., Wave Propagation in Intact and Jointed Calcium Carbonate $(\mathrm{CaCO} 3)$ Rock, DNA Report No. DNA-TR-95-47, (1996).

3. Miller, S.A., and Florence, A.L. Laboratory Particle Velocity Experiments on (JVE) Analog Rock, Report GL-TR-90-0279(I), Geophysics Laboratory, Air Force Systems Command (1990).

4. Gefken, P.R., and Florence, A.L. Spherical Wave Experiments With Frozen Limestone, Report, Project No. 3340, SRI International (1992). 